\title{
Quantification of Volatile Compounds in Wines by HS-SPME-GC/MS: Critical Issues and Use of Multivariate Statistics in Method Optimization
}

\author{
Sandra Pati ${ }^{1}$, Maria Tufariello ${ }^{2, *(\mathbb{D})}$, Pasquale Crupi ${ }^{3,4}$, Antonio Coletta $^{3}$, Francesco Grieco ${ }^{2, *(\mathbb{D})}$ \\ and Ilario Losito ${ }^{5}$
}

\section{check for} updates

Citation: Pati, S.; Tufariello, M.; Crupi, P.; Coletta, A.; Grieco, F.; Losito, I. Quantification of Volatile Compounds in Wines by HS-SPME-GC/MS: Critical Issues and Use of Multivariate Statistics in Method Optimization. Processes 2021, 9, 662. https://doi.org/10.3390/ pr9040662

Academic Editor: José Manuel Moreno-Rojas

Received: 18 March 2021

Accepted: 9 April 2021

Published: 9 April 202

Publisher's Note: MDPI stays neutral with regard to jurisdictional claims in published maps and institutional affiliations.

Copyright: (c) 2021 by the authors. Licensee MDPI, Basel, Switzerland. This article is an open access article distributed under the terms and conditions of the Creative Commons Attribution (CC BY) license (https:// creativecommons.org/licenses/by/ $4.0 /)$
1 Department of Agricultural, Food and Environmental Sciences (SAFE), University of Foggia, Via Napoli 25, 71100 Foggia, Italy; s.pati@unifg.it

2 CNR-Institute of Sciences of Food Production (ISPA), Via Prov. le, Lecce-Monteroni, 73100 Lecce, Italy

3 CREA-VE, Council for Agricultural Research and Economics, Research Centre for Viticulture and Enology, Via Casamassima 148, 70010 Turi (BA), Italy; pasquale.crupi@crea.gov.it (P.C.); antonio.coletta@crea.gov.it (A.C.)

4 Interdisciplinary Department of Medicine, University of Bari “Aldo Moro", P.zza Giulio Cesare 11, 70124 Bari, Italy

5 Department of Chemistry and SMART Inter-Department Research Center, University of Bari "Aldo Moro", Via E. Orabona 4, 70126 Bari, Italy; ilario.losito@uniba.it

* Correspondence: maria.tufariello@ispa.cnr.it (M.T.); francesco.grieco@ispa.cnr.it (F.G.); Tel.: +39-08-3242-2600 (M.T.); +39-08-3242-2612 (F.G.); Fax: +39-08-3242-2620 (M.T. \& F.G.)

\begin{abstract}
The aim of this review is to explore and discuss the two main aspects related to a HeadSpace Solid Phase Micro-Extraction Gas-Chromatography/Mass-Spectrometry (HS-SPME-GC/MS) quantitative analysis of volatile compounds in wines, both being fundamental to obtain reliable data. In the first section, recent advances in the use of multivariate optimization approaches during the method development step are described with a special focus on factorial designs and response surface methodologies. In the second section, critical aspects related to quantification methods are discussed. Indeed, matrix effects induced by the complexity of the volatile profile and of the non-volatile matrix of wines, potentially differing between diverse wines in a remarkable extent, often require severe assumptions if a reliable quantification is desired. Several approaches offering different levels of data reliability including internal standards, model wine calibration, a stable isotope dilution analysis, matrix-matched calibration and standard addition methods are reported in the literature and are discussed in depth here.
\end{abstract}

Keywords: wine; HS-SPME-GC/MS; multivariate statistical analysis; calibration

\section{Introduction}

A wine aroma profile (and thereby a volatile profile) is one of the most important quality criteria affecting wine acceptability by consumers [1]. Its characterization is very complex because volatile molecules usually belong to different classes such as alcohols, esters, aldehydes, acids, terpenes, phenols and lactones [2] with a wide range of polarity and concentrations. Furthermore, the non-volatile wine matrix affects the partitioning of aroma compounds between the matrix and the gas phase depending on their specific chemical properties and their interactions with aroma compounds [3].

An effective extraction from the aqueous wine matrix is essential for the accurate qualitative and quantitative analysis of wine volatiles. Therefore, various extraction and preconcentration approaches have been developed followed by separation and identification usually by mono-dimensional or bi-dimensional gas chromatography coupled to mass spectrometry (GC/MS, GC X GC/MS). Liquid-liquid [4], simultaneous distillation [5], solid phase [6], solid phase micro- [7], supercritical fluid [8] and stir bar sorptive extraction [9], 
among others, have been largely described for the analysis of wine volatile compounds [10]. On the other hand, headspace solid phase microextraction (HS-SPME), firstly described by Arthur and Pawliszyn [11], is considered to be one of the most effective techniques employed [10]. As HS-SPME is based on the partitioning of the analyte between the extracting phase immobilized on a fused silica fiber (as in all SPME approaches) and the headspace of the wine, it exploits a favorable transfer of volatile compounds into the latter. As with all SPME approaches, it combines sampling, analyte isolation and enrichment into one step and is suitable for full automation; moreover, as heat can be exploited for the desorption of the volatile analytes from the extracting phase, it does not require solvents either for the extraction or for the analyte desorption stage.

As with other SPME approaches, HS-SPME is usually a non-exhaustive extraction technique in which only a small percentage of the analyte is removed from the sample matrix. Both equilibrium and pre-equilibrium approaches can be employed. In the first case, enough time is available during the extraction step to reach the partitioning equilibrium between the sample matrix and the extraction phase and convection conditions do not affect the amount of analyte extracted. Under these conditions, if the sample volume $\left(\mathrm{V}_{\mathrm{s}}\right)$ is much larger than the product between the volume of the extracting phase on the fiber $\left(\mathrm{V}_{\mathrm{f}}\right)$ and the partition coefficient of the analyte between the fiber coating and the sample headspace $\left(\mathrm{K}_{\mathrm{fs}}\right)$ it can be easily demonstrated that the amount of analyte extracted is proportional to the sample concentration but it does not depend on the sample volume. Indeed, the following equation is valid:

$$
\mathrm{n}=\mathrm{K}_{\mathrm{fs}} \mathrm{V}_{\mathrm{f}} \mathrm{C}_{0}
$$

where $\mathrm{n}$ is the mass of an analyte absorbed on or partitioned into the coating and $\mathrm{C}_{0}$ is the initial concentration of the analyte in the sample [12].

In the second case, a short pre-equilibrium extraction is carried out and, if the convection is constant, the amount of extracted analyte is proportional to the extraction time. Even though the sensitivity is usually lower than that achievable with equilibrium extraction, the extraction time is shorter, thus reducing the overall analysis time. On the other hand, a non-equilibrium extraction requires a strict control of extraction conditions (e.g., convection, if present, time and temperature) in order to guarantee an acceptable reproducibility for quantitative analysis.

In all cases, the development of a quantitative SPME method requires a careful optimization of parameters affecting the extraction efficiency such as the type and volume of the extracting phase, the agitation method, the extraction time and sample modification $(\mathrm{pH}$, ionic strength, organic solvent content) and, especially when volatile analytes are involved, temperature. Moreover, as volatile compounds absorbed on/partitioned into the fiber coating are usually thermally desorbed by exposing the fiber to the heated space inside a GC injector before being separated into a GC column and detected, the desorption conditions of analytes (temperature, transport gas flow, eventual presence and characteristics of a liner into the GC injector) need to be optimized too.

The use of multivariate statistics approaches, in particular those pertaining to the design of experiments (DoE) instead of the classical univariate (one-at-a-time, OVAT) approach, has become increasingly relevant in recent years [13-15]. The increasing relevance of HS-SPME in wine analysis applications is illustrated by the linear increase in the number of publications on the topic occurred since the introduction of SPME (Figure 1). 


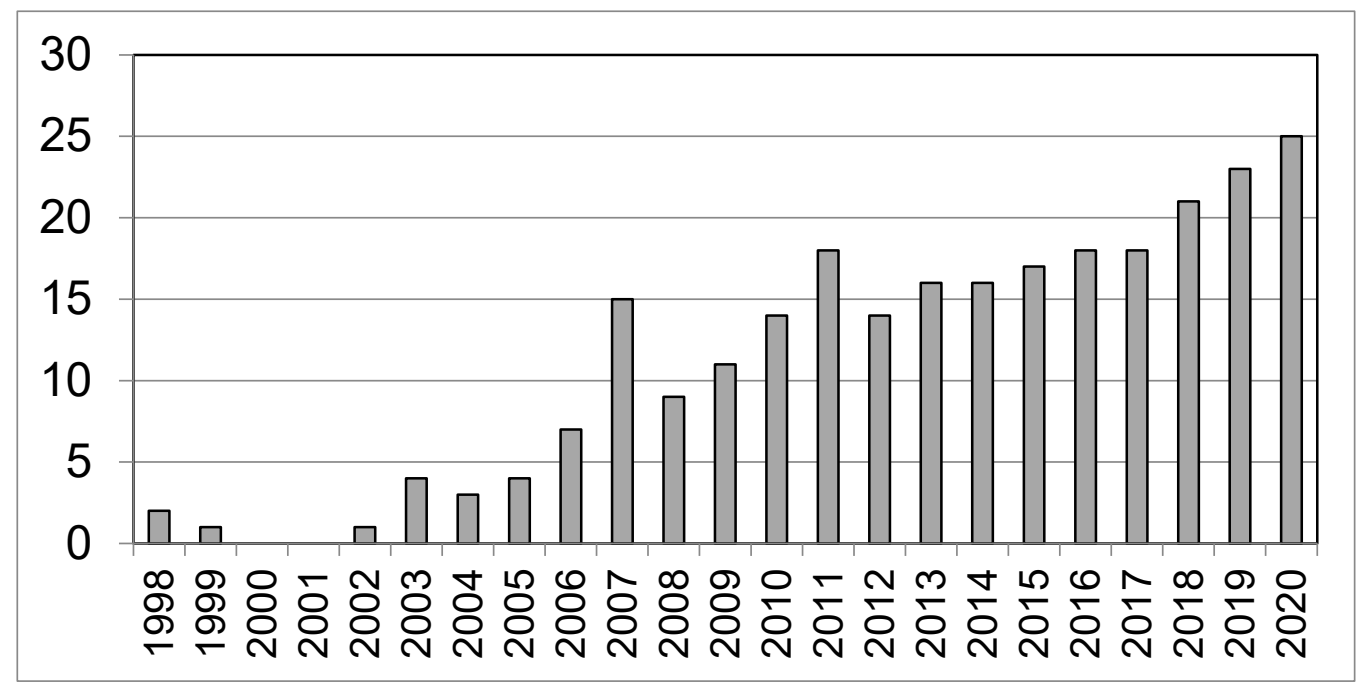

Figure 1. The number of papers related to Solid Phase Micro-Extraction (SPME) applications to wine.

In particular, the histogram in Figure 1 shows the number of papers related to SPME applications to wine based on a search on the Scopus database between 1998 and 2020 using the keywords "HS-SPME/wine/volatile" and excluding reviews, conference and data papers and book chapters. Despite the numerous reports describing SPME applications [2,16,17], papers concerning the critical issues of SPME-GC/MS quantification methods for wine volatiles are still limited and the number of rigorous quantitative applications reported in the literature is still low. This evidence can be considered a remarkable lack as divergent results concerning matrix effects $[18,19]$ and standardization methods $[20,21]$ have been reported in the literature for the quantification of wine volatiles.

Starting from the considerations made so far, this paper aims to review two relevant aspects related to the application of HS-SPME-GC/MS to the quantitative analysis of volatile compounds in wines: 1) recent advances in the use of optimization approaches in the method development stage; 2) critical aspects related to quantification methods so far reported. Indeed, both of these aspects are expected to contribute significantly to a successful application of HS-SPME-GC/MS methods pursuing the assessment of the safety, quality, authenticity and/or traceability of wines through the profile of their volatile compounds.

\section{Optimization of HS-SPME Parameters with Multivariate Statistical Analysis}

The success of HS-SPME depends on the analyte distribution between the matrix and the headspace, which is influenced in turn by a few parameters including the vapor pressure of volatiles, matrix ionic strength, stirring and equilibration time and temperature. The extraction time and temperature, the fiber sample distance and the nature and thickness of the fiber coating also play important roles in terms of extraction yield [15,22,23]. In light of this, statistical approaches able to optimize many factors simultaneously should be adopted to select the best conditions for the achievement of reliable and reproducible results. Multivariate statistics techniques can be successfully exploited for this purpose [24-27] (Figure 2). 


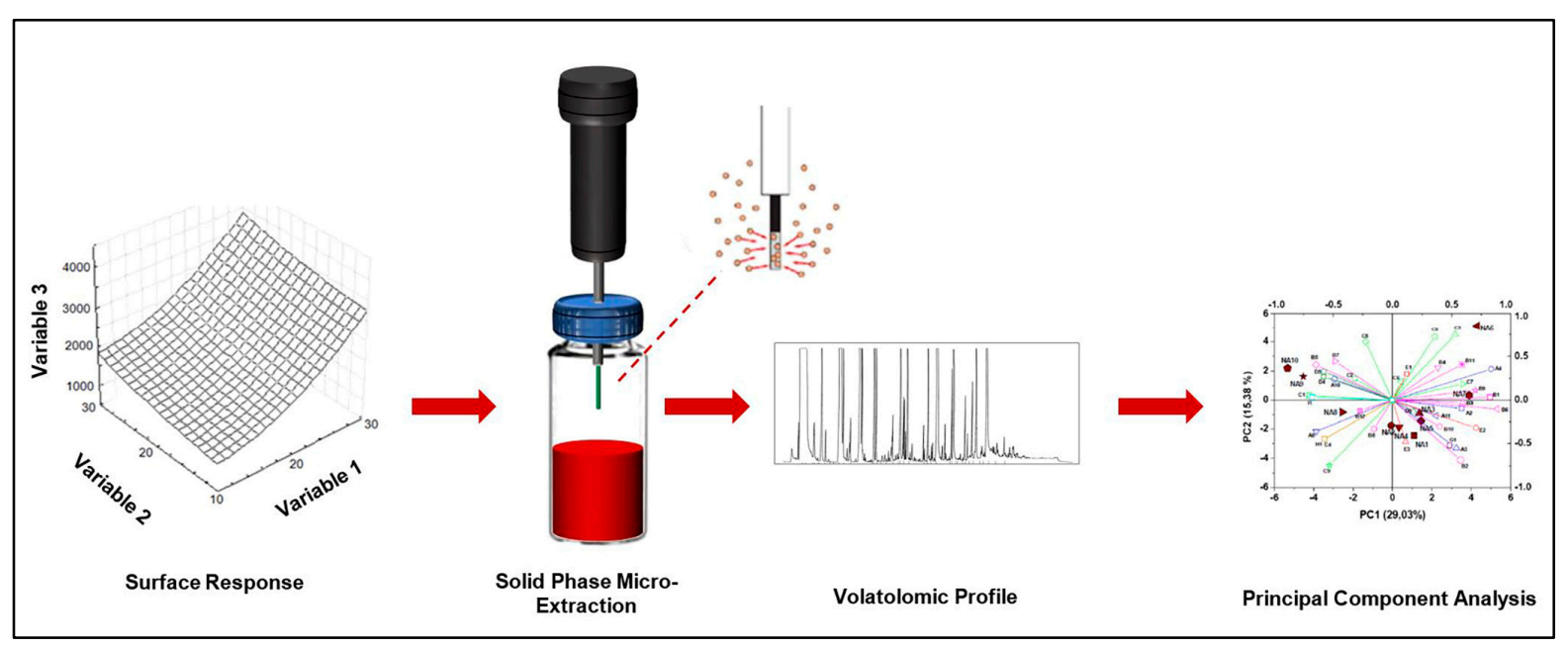

Figure 2. Optimization of Headspace Solid Phase Microxtraction (HS-SPME) parameters with a multivariate statistical analysis.

As a general approach, optimization procedures start with the definition of a measurable quantity, $Y$, as a reference parameter for the goodness/quality of the experiment itself. In most cases, the goodness of the experiment and the value of the $Y$ parameter are positively correlated. Once $Y$ is identified, factors $X_{i}$ (experimental parameters) with $i$ ranging from 1 to $k$ that are expected to affect the results of the experiment must be selected. In determining the best procedure for optimizing the factors, however, it must be taken into account that: (1) a range of admissible values has to be determined for each factor; (2) it is usually not possible to experimentally test all of the possible values of a single factor in its range nor all of the possible combinations of different factors.

Once the variability ranges have been established for the factors, optimization based on multivariate statistics can be achieved through two fundamental approaches related to the DoE: two-level factorial designs and response surface methodologies (RSM) [28-30] with the latter including, among others, central composite (CCD) [25,31], Doehlert matrix (DM) [32,33], three-level factorial (3K) and Box Behnken (BBD) designs [27].

Factorial designs are a class of experimental designs offering a relatively large amount of useful information from a small number of experiments; for this reason, they are often exploited for a screening of factors. When the number of experiments that can be carried out is limited, factorial designs offer an efficient way of obtaining the maximum information from these experiments. In this type of approach, a number of levels (different values of each factor within its variability range) is established. A measurement is made for each possible combination of the levels of each of the $k$ factors. The results are compared and the combination that maximizes the $Y$ parameter is determined by developing a relatively simple model based on the responses. In the two-level full factorial design, two levels per factor are established; the number of combinations and therefore the number of measurements to be made is thus $2^{\mathrm{k}}$. In a more generic case, if a number $\mathrm{N}$ of levels per factor is set, the number of measurements to be taken is $\mathrm{N}^{\mathrm{k}}$ [34-37].

This approach is quite different from the classical univariate approach (OVAT), which is based on the evaluation of the effect of one variable at a time with all other variables kept constant; thus, it is unable to provide information on the interactions among factors. It is worth noting that several univariate optimization studies have been conducted to determine the optimal conditions for the volatile extraction of wine by HS-SPME [15]. However, factorial designs may lead to similar accomplishments with a reduced number of experiments. Carrillo et al. [38] employed a full factorial design $\left(2^{4}\right)$ to establish the relative influence of four factors (type of fiber, temperature, pre-incubation time and sodium chloride addition) and their interactions on the chromatographic responses of extracted compounds in order to develop a method for the determination of oak-derived volatile compounds in wine. Robotti et al. [39] used an experimental design for the optimization of 
the SPME procedure according to both the maximum signal intensity and repeatability. In a study on Maresco sparkling wine volatiles, Tufariello et al. [21] focused on the equilibration of parameters and extraction times through a full two-factor three-level design with the purpose of optimizing the overall time of analysis and eventually finding an interaction factor between the two parameters affecting the analytical response.

A more complex approach to the DoE sometimes following the application of a factorial design is represented by the response surface methodology (RSM) [29,40,41]. In this case, the experiment is designed to provide a more refined model of the response surface, estimating interactions and even quadratic effects related to factors. RSM designs are used to find optimal process settings (in many cases as an improvement of those found using the factorial design), to troubleshoot process problems and weak points and make a product or process more robust against external and non-controllable influences. In this case, given $k$ factors, a quadratic model of response $Y$ is commonly adopted including $\mathrm{N}$ terms: a constant term, $k$ independent linear terms and $k$ independent quadratic terms (i.e., one for each factor in both cases) and $k(k-1) / 2$ mixed quadratic terms that take into account the interactions between all possible couples of different factors. A minimum of $\mathrm{N}$ measurements based on different combinations of experimental factor values is thus required to obtain the parameters of the model through the resolution of a linear system of $\mathrm{N}$ equations in $\mathrm{N}$ unknowns. Under these conditions, however, no estimate of the parameter variability (and then of its significance) can be obtained in this case unless a number of experiments greater than that of the parameters is performed, e.g., by replicating experiments for specific combinations of factors. A multivariate linear regression can be adopted to find the values of parameters (and obtain estimates of their variability) in this case.

A fundamental aspect to guarantee a good robustness of the results especially when the number of measurements has to be minimized is the choice of the combinations of the $k$ factor values. This is the aspect that most differentiates RSM approaches actually reported in the literature for the optimization of the extraction conditions for wine volatile compounds. Arcanjo et al. [31] reported the application of RSM based on a rotatable central composite design (RCCD) to improve the conditions for extracting volatiles from Isabel wine. In this work, the RCCD was used to evaluate the effects of three independent parameters: temperature, equilibration and extraction time on three different responses, namely, the total number of peaks detected upon a chromatographic separation, the total area under the detected peaks and the area of the peak of isoamyl acetate, a typical volatile compound present in wine headspace, to define the best conditions for a high extractability of volatiles. A central composite design (CCD) based on a factorial design plus eight axial points plus five replicates in the center of the design was chosen by Barros et al. [42] to develop a new automatic HS-SPME method for the determination of volatiles in white wines produced from several grape cultivars. The Box Behnken design (BBD) was applied in research for characterizing aroma-active monoterpenes in berries to determine optimum levels of three variables influencing the terpene recovery on SPME fiber: extraction temperature, extraction time and equilibrium time and consequently to display their linear and quadratic effects [29]. Recently, the DoE approach consisting of a definitive screening design (DSD) and latent variable modelling has been reported for the optimization of a method based on the HS-SPME-GC/MS analysis of volatile fatty acids in wine [14]. A DSD is a particular class of three levels of screening designs and is capable of providing estimates of the main effects that are unbiased or unconfounded regarding all second-order interactions and among themselves. The original version of the DSD was restricted to quantitative factors [43] but a more recent evolution extended the application to incorporate two-level categorical factors [44]. These designs require a low number of runs, one more than twice the number of factors. For more than six factors, they also have the potential capability to estimate the full quadratic model. 


\section{Matrix Effects and Calibration Approaches}

Wine volatile composition (influencing the headspace-extracting phase partition coefficient), the non-volatile wine matrix (influencing the liquid-headspace partition coefficient) along with ethanol levels (influencing both coefficients) were assessed as the factors mainly responsible for matrix effects $[3,19,45]$. Indeed, SPME is extremely sensitive to any experimental parameter that may affect the liquid-headspace and the headspace-extracting phase distribution coefficients.

Rocha et al. [45] investigated the effect of variations in the concentration of each analyzed standard on the other components of a model wine in order to clarify the extent of the changes in the concentration of one matrix component on the headspace equilibrium and, consequently, in the SPME absorption of the other liquid matrix components. The authors showed that the increase of the concentration of one compound results in a decrease of the absorption of all of the others and, as a consequence, of their relative response factors. Compounds with higher relative response factors were less influenced by the matrix composition. Thus, quantification by SPME was shown to be highly dependent on the matrix composition.

Rodríguez-Bencomo et al. [3] investigated the effects of five representative matrices, namely, a young white wine, a young red wine, an oak-aged red wine, a sparkling wine and a sweet, aged wine after deodorization, compared with a control model wine with no matrix effect. The authors found that the wine non-volatile fraction (composed of monosaccharides and disaccharides, amino acids, polyphenols and proteins and other high molecular weight compounds) strongly affected the volatility of odorous molecules through two different effects: retention and salting-out effects. In the first case, the volatile compound was retained by the non-volatile matrix (particularly by mannoproteins); thus, a decrease in the amount of aroma in the headspace was observed; in the second case there was the opposite situation, i.e., a few soluble non-volatile compounds (monosaccharides, disaccharides and amino acids) could bind water molecules thus decreasing the amount of free water in the matrix and increasing the concentration of the target compound, which in turn favored its volatilization. The behavior of the investigated matrices was quite different. Indeed, the non-volatile matrix composition is not the same in all wines; as an example, a red wine is significantly richer than a white wine in terms of polyphenols and tannins with effects on analyte solubility and on the interactions of the analyte matrix components.

Ferreira et al. [19] adopted three non-volatile matrices obtained from a white wine, a young red wine and an aged red wine, respectively, after complete dealcoholization and de-aromatization to investigate matrix effects in an SPME wine analysis. The authors revealed strong effects due to ethanol to the content of other major volatiles and to the composition of the non-volatile matrix depending on both the wine matrix composition and the compound nature. In particular, the authors showed that the effect of ethanol, which has potential effects on analyte solubility and on fiber extraction, due to potential competition, was higher than $20 \%$ of the total variability in 20 out of 61 investigated compounds. In general, the higher the ethanol level, the smaller the peak area. The effect of the levels of major volatile compounds accounted for more than $20 \%$ of the total variability in 19 cases and in a few, the effect of this factor became dominant. In most cases, the higher the level of major volatile compounds, the lower the signal. The authors attributed this behavior likely to competitive effects in the fiber exerted by some major compounds. The non-volatile matrix exerted an effect higher than $20 \%$ in 21 cases and in 11 cases became the dominant factor. In this case, the effects did not follow a well-defined trend, suggesting that intermolecular interactions occurred between a few analytes and matrix components.

In order to quantify volatile compounds in wine while keeping matrix effects into account, several approaches have been proposed including internal standards, model wine calibration, a stable isotope dilution analysis (SIDA), matrix-matched calibrations and standard addition methods (Table 1). 
Table 1. Advantages and disadvantages of SPME calibration methods.

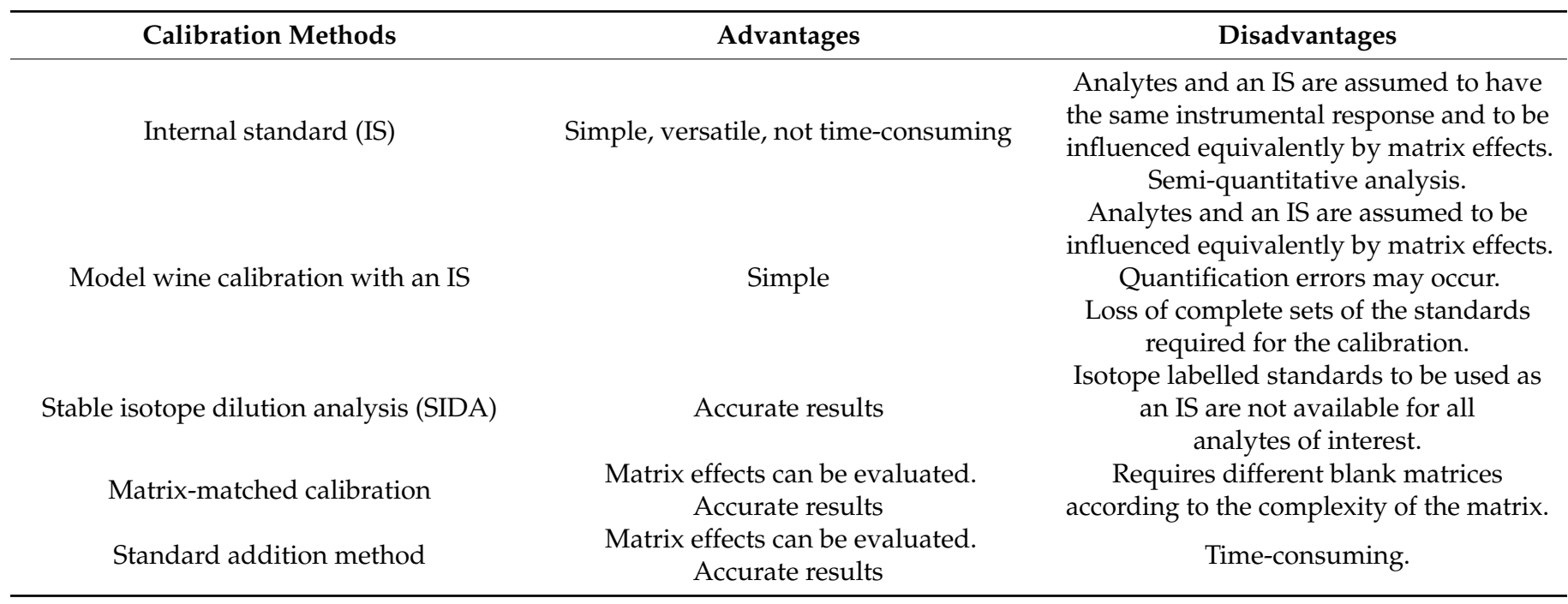

The use of an internal standard (IS) added to the matrix to be analyzed before extraction can compensate for matrix effects, losses of analytes during extraction and irreproducibility in instrumental responses but cannot fully avoid them; thus, quantification mistakes may occur. The IS must not be present (at least at detectable levels) in the samples, it should be similar in analytical behavior to the target analytes and it should be well-resolved from the latter. The compounds 4-methyl-2-pentanol and 2-octanol are the most used internal standards for volatile wine analysis [46,47]. An internal standard can also be employed for the equilibrium in fiber standardization. In this case, it is loaded on to the fiber coating prior to the extraction step instead of being spiked into the sample. The technique was developed for automated sampling from milliliter quantities of liquids in vials and used for the analysis of benzene, toluene, ethylbenzene, xylenes [48] and two carbamate pesticides [49] in a wine sample. However, no application has been yet reported in the literature for the determination of a wide range of volatile compounds in wine.

In general, quantitation with an IS is based on the calculation of the ratio between analytical responses (usually chromatographic peak areas) obtained for the analyte and the IS that is subsequently multiplied by the IS concentration. The analyte concentration is thus expressed as IS equivalents. By using this equation, the response factor (i.e., the ratio between a signal produced by an analyte and the quantity of the analyte producing the signal) of all analytes is supposed to be equal to the one of the IS. This is a quite drastic assumption when HS-SPME is adopted because it implies not only that analytes and the IS have the same instrumental response but also that they exhibit a similar behavior in terms of transfer into the headspace and of yield of extraction and then of desorption from the SPME coating. In other terms, they are expected to be influenced equivalently by matrix effects.

As it cannot be usually expected that the IS behaves the same as all of the analytes and, indeed, this requisite is generally not verified, quantification based on an IS is considered a semi-quantitative method. However, this approach is simple, versatile and can be successfully used when just a comparison of the number of individual compounds among samples is desired [50,51]. As the conversion of the analyte/IS response ratio into the analyte concentration can be misleading, many authors have expressed their results as a chromatographic peak area percentage for each volatile in order to compare it among the studied treatments [52,53]. In this case, an equal matrix effect on all analytes is also supposed to occur and the single peak area/total peak area ratio allows just a rough correction.

In model wine calibration, commercial standards are dissolved in ethanol and successively diluted in a wine model solution (e.g., $12 \%$ ethanol and $5 \mathrm{~g} / \mathrm{L}$ of tartaric acid at $\mathrm{pH} 3.2$ or more complex ethanolic solutions) to prepare the different levels of a calibration 
curve for each compound. Volatile compounds are analyzed at each calibration level using the same method as that adopted for real wine samples and linear regression is applied to calculate the respective concentration [54]. In this case, a different response of analytes due to their different nature can be inferred; however, no matrix effect can be considered. The internal standard can be added to the model wine calibration solutions and real samples to compensate for the losses of analytes during extraction, irreproducibility in the instrumental response and matrix effects. However, this approach is reliable only if the matrix effect is assumed to be equal for the IS and for all of the analytes. In this case, a calibration plot is developed by calculating the ratio of the peak area of the analyte to the IS one for calibration solutions containing different analyte concentrations with a fixed IS concentration. This ratio is subsequently used to calibrate the sample $[55,56]$. In order to improve the accuracy of results, the use of multiple standards has been also proposed [57].

When the approach of model wine calibration is used, the accuracy of the data can be established by the calculation of recovery $R$, which is obtained by comparing a wine sample spiked with known concentrations of the analytes ( $\mathrm{C}_{\text {added }}$, generally one or two levels) and an unspiked wine extracted and analyzed by the same procedure. Concentrations of the spiked $\left(\mathrm{C}_{\text {spiked }}\right)$ and unspiked $\left(\mathrm{C}_{\text {unspiked }}\right)$ samples are then calculated using the calibration line equation and $R$ is finally evaluated as: $\left.\left(C_{\text {spiked }}-C_{\text {unspiked }}\right) / C_{\text {added }}\right)$. However, percent recoveries exceeding 100 are often found for several analytes thus suggesting the presence of enhancive matrix effects, which are not easily confirmable if the recovery is calculated at a single or at two concentration levels [21].

Furthermore, a complete set of the standards required for the calibration is generally not commercially available. Therefore, the concentrations of volatile compounds for which it is not possible to establish calibration curves were estimated by several authors on the basis of the equations of compounds with the same functional groups and/or similar numbers of $\mathrm{C}$ atoms [55]. However, the ideal internal standard is an isotopically labeled analogue (usually its polydeuterated analogue) of the analyte of interest. Indeed, calibration with isotope labelled standards can produce satisfactory results though the compounds are not available for all analytes of interest and thus should be synthesized. In this case, each analyte is assumed to experience the same matrix effects as its isotopically labelled homologue.

Sejer Pedersen et al. [58] described a new method for the analysis of geraniol, nerol, linalool and $\alpha$-terpineol in wine based on the preparation of $\left[2 \mathrm{H}_{7}\right]$-geraniol, $\left[2 \mathrm{H}_{7}\right]$-nerol, $\left[2 \mathrm{H}_{7}\right]$-linalool and $\left[2 \mathrm{H}_{7}\right]-\alpha$-terpineol for the use of internal standards followed by liquidliquid extraction and a GC/MS analysis. Standard solutions with unlabeled compounds and internal standards were prepared for calibration purposes. For comparison, they also used an HS-SPME-GC/MS method finding an adequate sensitivity and limits of quantitation down to $1 \mu \mathrm{g} \mathrm{L} \mathrm{L}^{-1}$ or below with, however, a worse signal-to-noise ratio especially at lower concentrations.

Siebert et al. [59] first proposed the use of polydeuterated internal standards for stable isotope dilution analyses of 31 wine fermentation products by HS-SPME-GC/MS. Nine of the labelled standards were commercially available while 22 were synthesized. Capone et al. [60] developed a SIDA method for the quantitative analysis of seven C6 compounds. The two methods above [58,59] were successfully used by Ugliano et al. [61] and Bindon et al. [62]. Furthermore, Bindon et al. quantified isobutyl methoxypyrazine (IBMP), isopropyl methoxypyrazine (IPMP) and sec-butyl methoxypyrazine (SBMP) using IBMP-d3 as an internal standard. More recently, Tomasino et al. [63] used the SIDA approach to quantify monoterpene isomers in forty-six Pinot Gris wines by HS-SPME multidimensional gas chromatography mass spectrometry. Dang et al. [64] quantified volatile phenols using relative peak areas, i.e., the ratio between the peak area of the analyte and the one of the normalizing standard (d3-4-methylguaiacol). Bee-DiGregorio et al. [65] used deuterated internal standards for the linalool and 3-isobutyl-2-methoxypyrazine determinations. The authors prepared calibration solutions by spiking unlabeled and deuterated internal standards into Chardonnay juice or Pinot Noir homogenate containing no detectable linalool 
or 3-isobutyl-2-methoxypyrazine, respectively. However, although the SIDA has been shown to offer an effective strategy when a narrow range of analytes is investigated, this approach remains little used (just three out of twenty-five wine publications in 2020 used this method).

Among the further quantification methods cited before, matrix-matched calibration involves the preparation of several standard solutions in a sample matrix and then the extraction, desorption and analysis of volatile analytes under the same conditions are adopted for real samples so that a calibration line can be obtained in the presence of matrix effects. As usual, the calibration line equation can be subsequently used to estimate the concentrations of analytes in real samples once these are subjected to extraction and analysis and the corresponding analyte responses are obtained. Provided that standards are available for the analytes of interest, multi-analyte stock solutions can be prepared and then easily used for the preparation of matrix-matched multiple standards. Unfortunately, the matrix-matched calibration has a significant limitation as it requires a blank matrix, i.e., a matrix totally free from target analytes, to be available, which is a quite difficult requirement in the case of wine.

Liu et al. [66] firstly proposed the use of a volatile-free wine obtained by distillation for calibration purposes. The authors compared the chromatographic peak areas of 19 compounds, which were obtained using several model wine matrices including water, an $11.5 \%$ ethanol/water $(v / v)$ solution, a concentrated synthetic wine, a 'volatile-free' wine and a real wine spiked with the same number of analytes. The peak areas of the analytes decreased significantly with the increase in the complexity of the matrix composition suggesting the presence of interactions between the interfering substances and the analytes. The slopes of the calibration lines (taking into account the peak area relative to an internal standard) obtained using the model wine matrices were completely out of the confidence interval of the slope values related to the volatile-free wine and the real wine for most of the volatile compounds. Conversely, the slopes of the linear models obtained with the volatile-free wine were within the confidence interval of the slopes obtained with the real wine for 16 out of the 19. A few other authors have used different deodorized and representative wines $[3,19]$ according to the complexity of the matrix (e.g., young white wine, young red wine, oak-aged red wine), confirming the occurrence of interactions between the matrix and the analytes and the need to use a de-aromatized matrix for accurate calibrations. Furthermore, beside using a de-aromatized matrix, Ferreira et al. [19] proposed the employment of a large pool of internal standards and a calibration strategy based on the calculation of multivariate internal standards (MIS) as linear combinations of the normalized signals of multi-internal standards. However, in order to verify the occurrence of matrix effects when proposing other matrices for calibration, all of the authors cited so far $[3,19,66]$ compared the results with a calibration in real wine. In other words, they used the technique of standard addition as a control because this calibration technique is considered the most reliable.

The technique of standard addition [67] is based on the addition of known concentrations of the analyte of interest to multiple aliquots of the sample, leaving the sample volume (and the proportion ethanol/water) virtually unchanged. Thus, no effect of ethanol can be observed as no variation of its concentration occurs. The sample as such and the spiked samples are subsequently analyzed and a plot of the analytical response versus the added concentration is constructed for each analyte. In this case, the intercept of the regression line on the axis reporting added concentrations provides an estimate of the concentration in the original sample. In the context of the HS-SPME-GC/MS analysis of wine volatiles, the standard addition method was adopted by Carrillo et al. [38] for the quantification of volatile oak compounds in aged red wines. In this case, a significant difference with the results provided by the internal standard method was found for most of the compounds [38]. The standard addition method was also used by Pizarro et al. [68] to quantify haloanisoles and volatile phenols in both white and red wines. The method was also adopted in conjunction with vacuum-assisted HS-SPME-GC/MS for the determination 
of haloanisoles in red wines [69]. Recently, Tufariello et al. [21] compared a model wine calibration and the standard addition method for the quantification of volatiles in a white sparkling wine. As a result, they found that the quantification based on the model wine was not accurate for several analytes (with concentrations differing even by one order of magnitude) due to both suppressive and enhancive effects, depending on the analyte, on the final response exerted by the wine matrix. Therefore, although time-consuming, especially if a large number of samples has to be analyzed, the standard addition method should be the eligible method when accurate quantitative results for wine volatiles are highly desirable.

\section{Conclusions}

HS-SPME-GC/MS is a well-established technique for the analysis of volatile compounds in wine, offering undeniable and well-known advantages such as easiness of use, solventless analyte extraction and potentially high sensitivity. Unfortunately, the presence of many variables to optimize in the method development step may become a difficult challenge. However, the use of multivariate optimization approaches can be very useful to reduce the complexity of method optimization due to their capability to provide a lot of information when many factors are involved without requiring a high number of experiments. The quantification step of analytes is another critical point that needs to be carefully considered when performing an HS-SPME-GC/MS analysis of wine volatile compounds due to the potentially high relevance of matrix effects. Indeed, different quantification methods are usually adopted but none of them appear to be free from drawbacks such as failures in matrix effect reproduction (e.g., using model wines that cannot be considered reliable surrogates of real wines) or the need for time-consuming measurements (such as the standard addition method) or expensive compounds (such as isotopically labelled standards). The choice of the most appropriate quantification method should thus depend on a careful balance between the actual goal of the analysis (sometimes absolute concentrations of specific analytes implying more complex approaches are not strictly required) and practical aspects.

Author Contributions: Conceptualization, S.P. and I.L. review of literature-S.P., M.T., F.G., P.C., A.C.; writing-original draft preparation, M.T., S.P. and I.L.; writing-review and editing, S.P., M.T., F.G., P.C.; supervision, I.L. All authors have read and agreed to the published version of the manuscript.

Funding: This research received no external funding.

Institutional Review Board Statement: Not applicable.

Informed Consent Statement: Not applicable.

Data Availability Statement: Data sharing not applicable.

Acknowledgments: This work was partially supported by the Apulia Region projects: "Innovazione nella tradizione: tecnologie innovative per esaltare le qualità dei vini autoctoni spumante della murgia barese-INVISPUBA" (P.S.R. Puglia 2014/2020 Misura 16.2); “Birra: dal campo al boccale BE^2R" (P.S.R. Puglia 2014/2020 Misura 16.2). We would like to thank Domenico Genchi, Leone D'Amico, Vittorio Falco and Giovanni Colella of the Institute of Sciences of Food Production-CNR for their skilled technical support provided during the realization of this work.

Conflicts of Interest: The authors declare no conflict of interest.

\section{References}

1. Charters, S.; Pettigrew, S. The dimensions of wine quality. Food Qual. Prefer. 2007, 18, 997-1007. [CrossRef]

2. Panighel, A.; Flamini, R. Applications of Solid-Phase Microextraction and Gas Chromatography/Mass Spectrometry (SPMEGC/MS) in the Study of Grape and Wine Volatile Compounds. Molecules 2014, 19, 21291-21309. [CrossRef] [PubMed]

3. Rodriguez-Bencomo, J.J.; Munoz-Gonzalez, C.; Andujar-Ortiz, I.; Jose Martin-Alvarez, P.; Victoria Moreno-Arribas, M.; Angeles Pozo-Bayon, M. Assessment of the effect of the nonvolatile wine matrix on the volatility of typical wine aroma compounds by headspace solid phase microextraction/gas chromatography analysis. J. Sci. Food Agric. 2011, 91, 2484-2494. [CrossRef] [PubMed] 
4. Ferreira, V.; Rapp, A.; Cacho, J.; Hastrich, H.; Yavas, I.J. Fast and quantitative determination of wine flavor compounds using microextraction with Freon 113. J. Agric. Food Chem. 1993, 41, 1413-1420. [CrossRef]

5. Bosch-Fusté, J.; Riu-Aumatell, M.; Guadayol, J.M.; Caixach, J.; Lopez-Tamames, E.; Buxaderas, S. Volatile profiles of sparkling wines obtained by three extraction methods and gas chromatography-mass spectrometry (GC-MS) analysis. Food Chem. 2007, 105, 428-435. [CrossRef]

6. Ugliano, M.; Moio, L. Changes in the Concentration of Yeast-Derived Volatile Compounds of Red Wine during Malolactic Fermentation with Four Commercial Starter Cultures of Oenococcus oeni. J. Agric. Food Chem. 2005, 53, 10134-10139. [CrossRef]

7. Pozo-Bayón, M.A.; Pueyo, E.; Martín-Álvarez, P.J.; Polo, M.C. Polidimethylsiloxane solid-phase microextraction-gas chromatography method for the analysis of volatile compounds in wines. Its application to the characterization of varietal wines. J. Chromatogr. A 2001, 922, 267-275. [CrossRef]

8. Geffroy, O.; Morère, M.; Lopez, R.; Pasquier, G.; Condoret, J.S. Investigating the Aroma of Syrah Wines from the Northern Rhone Valley Using Supercritical $\mathrm{CO}_{2}$-Dearomatized Wine as a Matrix for Reconstitution Studies. J. Agric. Food Chem. 2020, 68, 11512-11523. [CrossRef]

9. Teodosiu, C.; Gabur, I.; Cotea, V.V.; Peinado, R.A.; López de Lerma, N. Alternative Winemaking Techniques to Improve the Content of Phenolic and Aromatic Compounds in Wines. Agriculture 2021, 11, 233.

10. Román, S.M.; Rubio-Bretón, P.; Pérez-Álvarez, E.P.; Garde-Cerdán, T. Advancement in analytical techniques for the extraction of grape and wine volatile compounds. Int. Food Res. J. 2020, 137, 109712. [CrossRef]

11. Arthur, C.L.; Pawliszyn, J. Solid-phase microextraction with thermal desorption using silica optical fibers. Anal. Chem. 1990, 62, 2145-2148. [CrossRef]

12. Zhang, Z.; Yang, M.J.; Pawliszyn, J. Solid-Phase Microextraction. Anal. Chem. 1994, 66, 844A-853A. [CrossRef]

13. Risticevic, S.; Niri, V.H.; Vuckovic, D.; Pawliszyn, J. Recent developments in solid-phase microextraction. Anal. Bioanal. Chem. 2009, 393, 781-795. [CrossRef]

14. Pereira, A.C.; Reis, M.S.; Leça, J.M.; Rodrigues, P.M.; Marques, J.C. Definitive Screening Designs and latent variable modelling for the optimization of solid phase microextraction (SPME): Case study-Quantification of volatile fatty acids in wines. Chemom. Intell. Lab. Syst. 2018, 179, 73-81. [CrossRef]

15. Azzi-Achkouty, S.; Estephan, N.; Ouaini, N.; Rutledge, D.N. Headspace solid-phase microextraction for wine volatile analysis. Crit. Rev. Food Sci. Nutr. 2017, 57, 2009-2020. [CrossRef]

16. Ouyang, G.; Pawliszyn, J. A critical review in calibration methods for solid-phase microextraction. Anal. Chim. Acta 2008, 627, 184-197. [CrossRef] [PubMed]

17. Risticevic, S.; Pawliszyn, J. Solid-Phase Microextraction in Targeted and Nontargeted Analysis: Displacement and Desorption Effects. Anal. Chem. 2013, 85, 8987-8995. [CrossRef]

18. Williams, C.; Buica, A. Comparison of an Offline SPE-GC-MS and Online HS-SPME-GC-MS Method for the Analysis of Volatile Terpenoids in Wine. Molecules 2020, 25, 657. [CrossRef] [PubMed]

19. Ferreira, V.; Herrero, P.; Zapata, J.; Escudero, A. Coping with matrix effects in headspace solid phase microextraction gas chromatography using multivariate calibration strategies. J. Chromatogr. A 2015, 1407, 30-41. [CrossRef] [PubMed]

20. Vaz Freire, L.M.T.; Costa Freitas, A.M.; Relva, A.M. Optimization of solid phase microextraction analysis of aroma compounds in a Portuguese Muscatel wine must. J. Microcolumn Sep. 2001, 13, 236-242. [CrossRef]

21. Tufariello, M.; Pati, S.; D'Amico, L.; Bleve, G.; Losito, I.; Grieco, F. Quantitative issues related to the headspace-SPME-GC/MS analysis of volatile compounds in wines: The case of Maresco sparkling wine. LWT_Food Sci. Technol. 2019, 108, 268-276. [CrossRef]

22. Câmara, J.S.; Arminda Alves, M.; Marques, J.C. Development of headspace solid-phase microextraction-gas chromatographymass spectrometry methodology for analysis of terpenoids in Madeira wines. Anal. Chim. Acta 2006, 555, 191-200. [CrossRef]

23. Kamgang Nzekoue, F.; Angeloni, S.; Caprioli, G.; Cortese, M.; Maggi, F.; Marini, U.; Marconi, B.; Perali, A.; Ricciutelli, M.; Sagratini, G.; et al. Fiber-sample distance, an important parameter to be considered in headspace solid-phase microextraction applications. Anal. Chem. 2020, 92, 7478-7484. [CrossRef] [PubMed]

24. Ferreira, D.C.; Hernandes, K.C.; Nicolli, K.P.; Souza-Silva, É.A.; Manfroi, V.; Zini, C.A.; Welke, J.E. Development of a method for determination of target toxic carbonyl compounds in must and wine using HS-SPME-GC/MS-SIM after preliminary GC $\times$ GC/TOFMS analyses. Food Anal. Methods 2019, 12, 108-120. [CrossRef]

25. Pellati, F.; Benvenuti, S.; Yoshizaki, F.; Bertelli, D.; Rossi, M.C. Headspace solid-phase microextraction-gas chromatography-mass spectrometry analysis of the volatile compounds of Evodia species fruits. J. Chromatogr. A 2005, 1087, 265-273. [CrossRef] [PubMed]

26. de Bona Sartor, S.; Sganzerla, M.; Teixeira Filho, J.; Teixeira Godoy, H. Multivariate optimization of volatile compounds extraction in Chardonnay wine by headspace-solid phase micro extraction and gas chromatography coupled with tandem mass spectrometry. Am. J. Anal. Chem. 2016, 7, 712-723. [CrossRef]

27. Muñoz-Redondo, J.M.; Ruiz-Moreno, J.M.; Puertas, B.; Cantos-Villar, E.; Moreno-Rojas, J.M. Multivariate optimization of headspace solid-phase microextraction coupled to gas chromatography-mass spectrometry for the analysis of terpenoids in sparkling wines. Talanta 2020, 208, 120483. [CrossRef]

28. Hanrahan, G.; Lu, K. Application of factorial and response surface methodology in modern experimental design and optimization. Crit. Rev. Anal. Chem. 2006, 36, 141-151. [CrossRef] 
29. Chmiel, T.; Kupska, M.; Wardencki, W.; Namieśnik, J. Application of response surface methodology to optimize solid-phase microextraction procedure for chromatographic determination of aroma-active monoterpenes in berries. Food Chem. 2017, 221, 1041-1056. [CrossRef]

30. Borges, T.H.; Ramalhosa, E.; Seiquer, I.; Pereira, J.A. Use of response surface methodology (RSM) for the identification of the best extraction conditions for Headspace Solid-Phase Micro Extraction (HS-SPME) of the volatile profile of cv. arbequina extra-virgin olive oil. Eur. J. Lipid Sci. Technol. 2018, 120, 1700356. [CrossRef]

31. Arcanjo, N.M.D.O.; Bezerra, T.K.A.; Da Silva, F.L.H.; Madruga, M.S. Optimization of the HS-SPME-GC/MS technique for determining volatile compounds in red wines made from Isabel grapes (Vitis labrusca). Food Sci. Technol. Camp. 2015, 35, 676-682. [CrossRef]

32. Martinez-Urunuela, A.; Gonzalez-Sáiz, J.M.; Pizarro, C. Optimisation of a headspace solid-phase microextraction method for the direct determination of chloroanisoles related to cork taint in red wine. J. Chromatogr. A 2004, 1056, 49-56. [CrossRef]

33. Kowalski, C.H.; Silva, G.A.D.; Poppi, R.J.; Godoy, H.T.; Augusto, F. Neuro-genetic multi-optimization of the determination of polychlorinated biphenyl congeners in human milk by headspace solid phase microextraction coupled to gas chromatography with electron capture detection. Anal. Chim. Acta 2007, 585, 66-75. [CrossRef]

34. Deming, S.N.; Morgan, S.L. Experimental Design: A Chemometric Approach; Elsevier: Amsterdam, The Netherlands, 1993.

35. Lundstedt, T.; Seifert, E.; Abramo, L.; Thelin, B.; Nyström, A.; Pettersen, J.; Bergman, R. Experimental design and optimization. Chemom. Intell. Lab. Syst. 1998, 42, 3-40. [CrossRef]

36. Otto, M. Chemometrics: Statistics and Computer Application in Analytical Chemistry; Wiley-VCH: Hoboken, NJ, USA, 1999.

37. Hanrahan, G.; Zhu, J.; Gibani, S.; Patil, D.G. Chemometrics: Experimental design. In Encyclopedia of Analytical Science; Worsfold, P.J., Townshend, A., Poole, C.F., Eds.; Elsevier: Oxford, UK, 2005; Volume 2, pp. 8-13.

38. Carrillo, J.D.; Garrido-López, A.; Tena, M.T. Determination of volatile oak compounds in wine by headspace solid-phase microextraction and gas chromatography-mass spectrometry. J. Chromatogr. A 2006, 1102, 25-36. [CrossRef]

39. Robotti, E.; Campo, F.; Riviello, M.; Bobba, M.; Manfredi, M.; Mazzucco, E.; Gosetti, F.; Calabrese, G.; Sangiorgi, E.; Marengo, E. Optimization of the Extraction of the Volatile Fraction from Honey Samples by SPME-GC-MS, Experimental Design, and Multivariate Target Functions. J. Chem. 2017, 2017, 6437857. [CrossRef]

40. Burin, V.M.; March, S.; de Revel, G.; Bordignon-Luiz, M.T. Development and validation of method for heterocyclic compounds in wine: Optimization of HS-SPME conditions applying a response surface methodology. Talanta 2013, 117, 87-93. [CrossRef]

41. Torchio, F.; Giacosa, S.; Vilanova, M.; Segade, S.R.; Gerbi, V.; Giordano, M.; Rolle, L. Use of response surface methodology for the assessment of changes in the volatile composition of Moscato bianco (Vitis vinifera L.) grape berries during ripening. Food Chem. 2016, 212, 576-584. [CrossRef]

42. Barros, E.P.; Moreira, N.; Pereira, G.E.; Ferreira Leite, S.G.; Rezende, C.M.; Guedes de Pinho, P. Development and validation of automatic HS-SPME with a gas chromatography-ion trap/mass spectrometry method for analysis of volatiles in wines. Talanta 2012, 101, 177-186. [CrossRef]

43. Jones, B.; Nachtsheim, C.J. A class of three-level designs for definitive screening in the presence of second-order effects. J. Qual. Technol. 2011, 43, 1-15. [CrossRef]

44. Jones, B.; Nachtsheim, C.J. Definitive Screening Designs with Added Two-Level Categorical Factors. J. Qual. Technol. 2013, 45, 121-129. [CrossRef]

45. Rocha, S.; Ramalheira, V.; Barros, A.; Delgadillo, I.; Coimbra, M.A. Headspace Solid Phase Microextraction (SPME) Analysis of Flavor Compounds in Wines. Effect of the Matrix Volatile Composition in the Relative Response Factors in a Wine Model. J. Agric. Food Chem. 2001, 49, 5142-5151. [CrossRef] [PubMed]

46. Terpou, A.; Ganatsios, V.; Kanellaki, M.; Koutinas, A.A. Entrapped Psychrotolerant Yeast Cells within Pine Sawdust for Low TemperatureWine Making: Impact on Wine Quality. Microorganisms 2020, 8, 764. [CrossRef] [PubMed]

47. Moreno-Olivares, J.D.; Paladines-Quezada, D.; Fernández-Fernández, J.I.; Bleda-Sánchez, J.A.; Martínez-Moreno, A.; Gil-Muñoz, R. Study of aromatic profile of different crosses of Monastrell white wines. J. Sci. Food Agric. 2020, 100, 38-49. [CrossRef] [PubMed]

48. Wang, Y.; O’Reilly, J.; Chen, Y.; Pawliszyn, J. Equilibrium in-fibre standardisation technique for solid-phase microextraction. J. Chromatogr. A 2005, 1072, 13-17. [CrossRef] [PubMed]

49. Zhou, S.N.; Zhang, X.; Ouyang, G.; Es-haghi, A.; Pawliszyn, J. On-Fiber Standardization Technique for Solid-Coated Solid-Phase Microextraction. Anal. Chem. 2007, 79, 1221-1230. [CrossRef]

50. Furdíková, K.; Machŷnáková, A.; Drtilová, T.; Špánik, I. Comparison of different categories of slovak tokaj wines in terms of profiles of volatile organic compounds. Molecules 2020, 25, 669. [CrossRef] [PubMed]

51. Karimali, D.; Kosma, I.; $\cdot$ Badeka, A. Varietal classification of red wine samples from four native Greek grape varieties based on volatile compound analysis, color parameters and phenolic composition. Eur. Food Res. Tech. 2020, 246, 41-53. [CrossRef]

52. Almeida Santos, C.V.; Gomes da Silva, M.; Cabrita, M.J. Impact of $\mathrm{SO}_{2}$ and bentonite addition during fermentation on volatile profile of two varietal white wines. LWT Food Sci. Technol. 2020, 133, 109893. [CrossRef]

53. Castillo, M.; da Silva, E.; Câmara, J.S.; Khadem, M. Molecular identification and VOMs characterization of Saccharomyces cerevisiae strains isolated from Madeira region winery environments. Processes 2020, 8, 1058. [CrossRef]

54. Oliveira, A.S.; Furtado, I.; Bastos, M.D.L.; de Pinho, P.G.; Pinto, J. The influence of different closures on volatile composition of a white wine. Food Packag. Shelf Life 2020, 23, 100465. [CrossRef] 
55. Kong, C.-L.; Li, A.-H.; Suc, J.; Wang, X.-C.; Chen, C.-Q.; Tao, Y.-S. Flavor modification of dry red wine from Chinese spine grape by mixed fermentation with Pichia fermentans and S. cerevisiae. LWT Food Sci. Technol. 2019, 109, 83-92. [CrossRef]

56. Hu, K.; Jin, G.J.; Xu, Y.H.; Tao, Y.S. Wine aroma response to different participation of selected Hanseniaspora uvarum in mixed fermentation with Saccharomyces cerevisiae. Int. Food Res. J. 2018, 108, 119-127. [CrossRef] [PubMed]

57. Rebière, L.; Clark, A.C.; Schmidtke, L.M.; Prenzler, P.D.; Scollary, G.R. A robust method for quantification of volatile compounds within and between vintages using headspace-solid-phase micro-extraction coupled with GC-MS-application on Semillon wines. Anal. Chim. Acta 2010, 660, 149-157. [CrossRef]

58. Sejer Pedersen, D.; Capone, D.L.; Skouroumounis, G.K.; Pollnitz, A.P.; Sefton, M.A. Quantitative analysis of geraniol, nerol, linalool, and $\alpha$-terpineol in wine. Anal. Bioanal. Chem. 2003, 375, 517-522. [CrossRef]

59. Siebert, T.E.; Smyth, H.E.; Capone, D.L.; Neuwöhner, C.; Pardon, K.H.; Skouroumounis, G.K.; Herderich, M.J.; Sefton, M.A.; Pollnitz, A.P. Stable isotope dilution analysis of wine fermentation products by HS-SPME-GC-MS. Anal. Bioanal. Chem. 2005, 381, 937-947. [CrossRef]

60. Capone, D.L.; Black, C.A.; Jeffery, D.W. Effects of 3-mercaptohexan-1-ol precursor concentrations from prolonged storage of Sauvignon blanc grapes prior to crushing and pressing. J. Agric. Food Chem. 2012, 60, 3515-3523. [CrossRef]

61. Ugliano, M.; Siebert, T.; Mercurio, M.; Capone, D.L.; Henschke, P.A. Volatile and color composition of young and model-aged Shiraz wines as affected by diammonium phosphate supplementation before alcoholic fermentation. J. Agric. Food Chem. 2008, 56, 9175-9182. [CrossRef]

62. Bindon, K.; Varela, C.; Kennedy, J.; Holt, H.; Herderich, M. Relationships between harvest time and wine composition in Vitis vinifera L. cv. Cabernet Sauvignon 1. Grape and wine chemistry. Food Chem. 2013, 138, 1696-1705. [CrossRef]

63. Tomasino, E.; Song, M.; Fuentes, C. Odor Perception Interactions between Free Monoterpene Isomers and Wine Composition of Pinot Gris Wines. J. Agric. Food Chem. 2020, 68, 3220-3227. [CrossRef]

64. Dang, C.; Jiranek, V.; Taylor, D.K.; Wilkinson, K.L. Removal of Volatile Phenols From Wine Using Crosslinked Cyclodextrin Polymers. Molecules 2020, 25, 910. [CrossRef]

65. Bee-DiGregorio, M.Y.; Feng, H.; Pan, B.S.; Dokoozlian, N.K.; Sacks, G.L. Polymeric Sorbent Sheets Coupled to Direct Analysis in Real Time Mass Spectrometry for Trace-Level Volatile Analysis-A Multi-Vineyard Evaluation Study. Foods 2020, 9, 409. [CrossRef]

66. Liu, M.; Zeng, Z.; Tian, Y. Elimination of matrix effects for headspace solid phase microextraction of important volatile compounds in red wine using a novel coating. Anal. Chim. Acta 2005, 540, 341-353. [CrossRef]

67. Bader, M. A systematic approach to standard addition methods in instrumental analysis. J. Chem. Educ. 1980, 57, 703-706. [CrossRef]

68. Pizarro, C.; Peres-del-Notario, N.; Gonzalez-Saiz, J.M. Multiple headspace solid-phase microextraction for eliminating matrix effect in the simultaneous determination of haloanisoles and volatile phenols in wines. J. Chromatogr. A 2007, 1166, 1-8. [CrossRef]

69. Vakinti, M.; Mela, S.M.; Fernandez, E.; Psillakis, E. Room temperature and sensitive determination of haloanisoles in wine using vacuum-assisted headspace solid-phase microextraction. J. Chromatogr. A 2019, 1602, 142-149. [CrossRef] 